\title{
Functional outcome and complication following THA through modified direct anterior approach correlated to cadaveric study: are there any differences in Asian hip?
}

Ong-art Phruetthiphat ${ }^{1 *}$ (D), Vasin Sangthumprateep ${ }^{1}$, Songpol Trakulngernthai ${ }^{1}$, Noppadol Aegakkatajit ${ }^{1}$ Thanainit Chotanaphuti ${ }^{1}$ and Malee Chanpoo ${ }^{2}$

\begin{abstract}
Background: Direct anterior approach (DAA) has several advantages including shorter length of hospital stay, faster recovery, and better functional outcome while this approach may cause damage to the lateral femoral cutaneous nerve (LFCN) as high as $81 \%$ in the works of literature. Not much data has identified the LFCN pattern in the Asian population. Therefore, the purpose of our study was to identify characteristics of the LFCN patterns representing an Asian hip, which would aid to provide the most appropriate incision of modified direct anterior approach (MDAA) for total hip arthroplasty (THA), and to identify the clinical outcome and complications following THA through MDAA correlated with cadaveric hip in the Asian population.

Methods: After IRB approval, a cadaveric study was done to identify pattern and course of the LFCN in Asian population. The MDAA defined as the incision 2 fingerbreadths posteriorly to anterior superior iliac spine to avoid injury to the LFCN. The clinical phase identified 32 patients who underwent THA because of late-stage osteoarthritis of the hip. The anterolateral skin numbness was measured along tensor fascia lata between 2 weeks until 2 years. The functional outcome assessed by Harris Hip Score (HHS) and complications were evaluated in all patients.

Results: The characteristics of the LFCN from cadaveric study (phase 1) was predominantly in sartorius type (60.0\%) followed by posterior type (26.6\%), fan type (6.7\%), and variant type (6.7\%). The clinical phase demonstrated that 23 patients (71.9\%) had no numbness while 9 patients (28.1\%) came with numbness after undergoing THA through the MDAA. Finally, a small area of skin numbness remained in only 3 patients (9.4\%) at 2 years follow-up. Additionally, there was no significant difference in functional score at 2 years follow-up (89.0 vs 91.2, $p=0.422$ ) between those with LFCN injury and those without LFCN injury.
\end{abstract}

\footnotetext{
*Correspondence: ophruetthiphat@gmail.com; ongart-phr1@hotmail.com 'Orthopedic Department, Phramongkutklao Hospital, 315 Ratchvidhi Road, Thung Phaya Thai, Ratchathewee, Bangkok 10400, Thailand

Full list of author information is available at the end of the article
}

(c) The Author(s). 2021 Open Access This article is licensed under a Creative Commons Attribution 4.0 International License, which permits use, sharing, adaptation, distribution and reproduction in any medium or format, as long as you give appropriate credit to the original author(s) and the source, provide a link to the Creative Commons licence, and indicate if changes were made. The images or other third party material in this article are included in the article's Creative Commons licence, unless indicated otherwise in a credit line to the material. If material is not included in the article's Creative Commons licence and your intended use is not permitted by statutory regulation or exceeds the permitted use, you will need to obtain permission directly from the copyright holder. To view a copy of this licence, visit http://creativecommons.org/licenses/by/4.0/ The Creative Commons Public Domain Dedication waiver (http://creativecommons.org/publicdomain/zero/1.0/) applies to the data made available in this article, unless otherwise stated in a credit line to the data. 
Conclusions: The LFCNs were divided into four types. Modified direct anterior approach, which is an alternative approach for THA, allowing for a lower rate of skin numbness and faster recovery without hip dislocation, abductor weakness, and serious nerve complication. Functional outcome was comparable with and without LFCN injury.

Level of evidence: Level II, prospective observation study

Keywords: Modified direct anterior approach, Lateral femoral cutaneous nerve of thigh, Cadaveric study, Clinical study, Functional outcome, Complication, Asian, Total hip arthroplasty

\section{Introduction}

THA is one of the most successful procedures for severe OA hip to reduce pain, improve function, and increase the quality of life $[1,2]$. Several approaches in THA can be utilized [3]. The standard posterolateral approach requires splitting of the posterior hip capsule and the external rotators, which is associated with high dislocation rates [4-7] while the anterolateral approach is more resistant to dislocation, but detaching the gluteus medius and minimus insertions from the greater trochanter are associated with abductor dysfunction and postoperative limp [3, 8, 9]. Direct anterior approach can be applied for several procedures on orthopedic surgery including femoroacetabular impingement or total hip arthroplasty for adult hip reconstruction [10-13], septic arthritis, or developmental hip dysplasia in pediatric orthopedic septic arthritis, or developmental hip dysplasia in pediatric orthopedic surgery [14-16] and irreducible closed reduction in displaced femoral neck fracture [17]. However, an anterior approach to the hip joint through an interval between sartorius and tensor fascia lata may cause damage to the lateral femoral cutaneous nerve (LFCN) as high as $81 \%$ in the literatures [18-20]. Recent publication has demonstrated three branching patterns and route of the LFCN from European specimens [21]. Conversely, not much data has identified the LFCN in the Asian population. Therefore, the purpose of our study was to identify characteristics of the LFCN patterns representing an Asian hip, which would aid to provide the most appropriate incision of modified direct anterior approach (MDAA) for total hip arthroplasty (THA), and to identify the clinical outcome and complications following THA through MDAA correlated with cadaveric hip in the Asian population.

\section{Materials and methods}

\section{Phase 1: Cadaveric study}

After Institutional Research Board Approval, 34 lateral femoral cutaneous nerve (LFCN) of thighs were done from 17 formalin-embalmed cadavers. We dissected the skin and subcutaneous tissue, in layers, from the abdomen to the thigh. The abdomen was opened, eviscerated, and the retroperitoneal fat was removed. We further identified the psoas muscle, lumbosacral plexus, especially LFCN structure and route. The lateral femoral cutaneous nerves of the thigh were carefully studied to identify their structure, boundary, branches, and nerve passage. Four cadavers were excluded because they were imperfect specimens. Finally, the study contained 30 specimens (24 specimens from male donors and 6 from female donors; mean age at death of 84 years; range, 76 to 94 years). All specimens were dissected following the dissection protocol through an ilioinguinal approach. The LFCN branching pattern and distribution within the proximal aspect of thigh were described with respect to 4 important landmarks; the ASIS, the inguinal ligament, the medial border of tensor fascia lata, and the lateral border of the sartorius.

The characteristics of the LFCN from cadaveric study (phase 1) was predominantly in sartorius type (60.0\%) followed by posterior type (26.6\%), fan type (6.7\%), and variant type $(6.7 \%)$ as shown in Fig. 1. The dominant branch of this nerve downwardly crossed along the lateral border of the sartorius muscle. Therefore, we further applied the most appropriate incision (the modified direct anterior approach; MDAA) for THA in 32 patients with late stage of osteoarthritic hip. The MDAA defined as the incision 2 fingerbreadths posteriorly to ASIS to avoid injury to the LFCN as shown in Fig. 2 (intraoperative picture).

\section{Phase 2: Clinical study}

A prospectively observational study of 32 patients who underwent primary THAs for late-stage of osteoarthritis (OA) of the hip (26 patients from primary OA and 6 patients from secondary $\mathrm{OA}$ ) of the hip between January 2016 and December 2017, was evaluated for areas of skin numbness and clinical outcomes following THA from a 2-week to a 2-year follow-up (FU). All patients had no clinical symptoms of lumbar nerve root pathology associated with lower spinal problem, no history of diabetic neuropathy, and no previous scar around the affected hip. Primary OA hip was defined as osteoarthritis of the hip which has no specific cause while secondary OA hip was defined as osteoarthritis of the hip with specific cause (osteonecrosis, posttraumatic, and developmental dysplasia of the hip). Patients' variables reviewed were demographic data, comorbidity including 


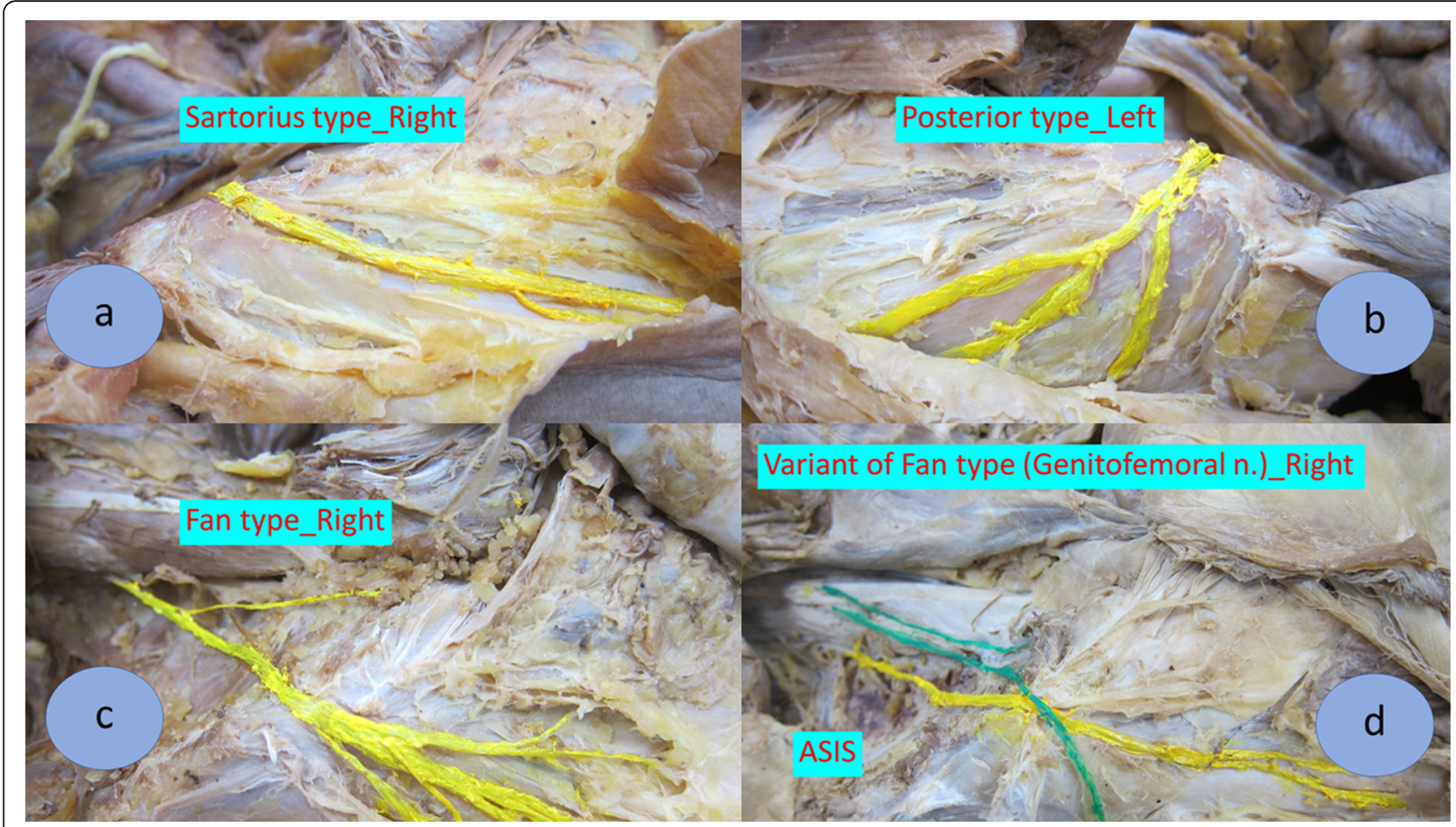

Fig. 1 The pattern of lateral femoral cutaneous nerve of thigh (LFCN): (a) sartorius type, (b) posterior type, (c) fan type, and (d) variant type. ASIS is anterior superior iliac spine; Genitofemoral $n$. is genitofemoral nerve

American Society Anesthesiologist (ASA) classification and Charlson comorbidity index (CCI), preoperative visual analog scale (VAS), preoperative Harris hip score (HHS), intraoperative parameters including operative time (minutes), blood loss (milliliter), and intraoperative complication.

\section{Surgical procedure}

All patients were performed on a single surgeon under spinal anesthesia. During an operation, all patients underwent a uniform surgical pattern, including a modified direct anterior approach skin incision, laying down on non-Hana surgical table, and a single prosthetic design (Pinnacle cup ${ }^{\oplus}$, Marathon liner ${ }^{\oplus}$, Metal head, Corail stem $^{\oplus}$, Johnson \& Johnson, USA). To maximally avoid injury to the LFCN, all patients underwent the skin incision 2 fingerbreadths posteriorly to ASIS as shown in Fig. 2. The further dissection was deeply through the posterior one third of tensor fascia lata to avoid the major pattern (sartorius type) of the LFCN. We

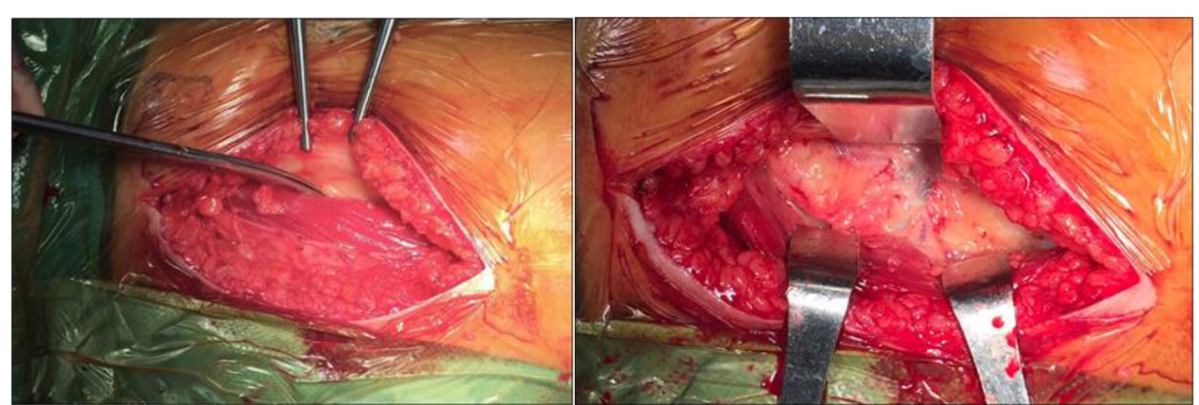

Fig. 2 The modified direct anterior approach (MDAA): skin incision performed posteriorly to ASIS 2 fingerbreadths (left) and further dissection was deeply through the posterior one-third of tensor fascia lata (right) 
hypothesized that the application of the MDAA skin incision can avoid injury to the LFCN between $60 \%$ and $86.6 \%$ (60.0\% from sartorius type and $26.6 \%$ from posterior type). However, we could not avoid injury to fan type $(6.7 \%)$ and variant type $(6.7 \%)$ to these nerves using this approach.

\section{Measurement of numbness and follow-up}

Area of anterior skin numbness was periodically evaluated at 6 weeks, 3 months, 6 months, 1 year, 1.5 year, and 2 years follow-up (FU). The measurement executed below the ASIS downwardly and the iliotibial band (anterolateral aspect of upper thigh) with a pin prick sensation until normal sensation occurred. We measured the skin numbness caused by LFCN injury, defined as an absence of normal sensation compared to the contralateral thigh. In addition, measurements of numbness performed by two physicians who were not involved in the operative field had averaged results.

\section{Measurement of functional outcome and complication}

Functional outcome following THA was measured by Harris hip score (HHS) at 2 years follow-up. The complication included paresthesia between numbness until meralgia paresthetica, abductor weakness (Trendelenburg gait), surgical site infection, and periprosthetic joint infection.

\section{Statistical analysis}

Data description was based on means and standard deviation for continuous variables and absolute and relative frequencies for categorical variables. A standard Student's $t$ test was used for continuous variables while the Chi-squared test was applied for categorical variables. Statistical analysis was performed using STATA/MP 12 with statistical significance set to $P<0.05$.

Table 1 Demographic data of lateral femoral cutaneous nerves of thigh

\begin{tabular}{|c|c|c|c|c|}
\hline \multirow{2}{*}{$\begin{array}{l}\text { Baseline } \\
\text { characteristics }\end{array}$} & \multicolumn{4}{|l|}{ Type } \\
\hline & Sartorius & Posterior & Fan & Variant \\
\hline \multicolumn{5}{|l|}{ 1. Site } \\
\hline Right $(n=17)(56.7 \%)$ & 11 & 4 & 1 & 1 \\
\hline Left $(n=13)(43.3 \%)$ & 7 & 4 & 1 & 1 \\
\hline$p$ value & 0.918 & & & \\
\hline \multicolumn{5}{|l|}{ 2. Gender } \\
\hline Male $(n=24)(80 \%)$ & 14 & 7 & 1 & 2 \\
\hline Female $(n=6)(20 \%)$ & 4 & 1 & 1 & 0 \\
\hline$p$ value & 0.740 & & & \\
\hline Total (100\%) & $18(60.0 \%)$ & $8(26.6 \%)$ & $2(6.7 \%)$ & $2(6.7 \%)$ \\
\hline
\end{tabular}

\section{Result}

\section{Phase 1: Cadaveric study}

The LFCN was identified in 30 cadavers. There were 24 men $(80.0 \%)$ and 6 women $(20.0 \%)$ with ages ranging from 76 to 94 years (average age, 84.4 years). These nerves were classified into 4 patterns (as shown in Table 1 and Fig. 1): sartorius type $(60.0 \%, n=18)$, posterior type $(26.6 \%, n=$ $8)$, fan type $(6.7 \%, n=2)$, and variant type $(6.7 \%, n=2)$. The sartorius type defined as the main branch crossed along the lateral border of the sartorius muscle, the posterior type was characterized by a strong posterior nerve branch along the tensor fascia lata, the fan type was characterized by several spreading nerve branches with equal thickness, while the variant type defined as the combination of two nerves characterized by genitofemoral nerve joins with the LFCN.

The anatomic distribution of the LFCN demonstrated correlation of these nerves with an important anatomical landmark as shown in Table 2 . In most of the 30 dissections $(63.3 \%, n=19)$, the nerves cross overed the tensor fascia lata (TFL) while the others passed under the TFL (36.7\%, $n=11)$. No significant difference was observed between the right and the left sides with respect to relationship among the nerve types (Chi-square test, $p=$ 0.918 ) and there was no significant difference between gender $(p=0.740)$ and nerve patterns. All of the nerves crossed medially to the ASIS. Most of them branched out inferiorly to the inguinal ligament $(90.0 \%, n=27)$. According to the branches of the LFCN, almost of them $(86.7 \%, n=26)$ had at least 2 branches while only 4 dissections $(13.3 \%)$ had no branch.

\section{Phase 2: Clinical result}

Patients' demographics and comorbidities were demonstrated in Table 3. All patients underwent THA by using the modified direct anterior approach (MDAA, Fig. 2) to avoid an injury to this nerve. As a result (Table 4), 23 patients $(71.9 \%)$ had no numbness after surgery while 9 patients $(28.1 \%)$ came with numbness after undergoing THA through the MDAA. The average recovery of numbness was approximately 12.6 months (median 12.0 months). In those patients with numbness, 4/9 were fully recovered within 6 months and 2/9 were fully recovered at 1 year, while 3/9 were partially recovered at 2 years follow-up. Additionally, none of the patients had any surgical complications (Table 5) including neuropathic pain (meralgia paresthetica) and Trendelenburg gait, while one patient died from pneumonia with sepsis at 3 years after THA (3.1\%, $n=1)$. Conversely, most of them (29 out of 32) (90.6\%) had good to excellent functional outcome at 2 years follow-up $(53.1 \%$ were excellent, $37.5 \%$ were good, and $9.4 \%$ were fair). Additionally, the pain score assessed by VAS ( 0.8 vs $8.2, p<0.001)$ and the HHS (89.6 vs 42.8 , $p<0.001)$ were significantly improved after THA through 
Table 2 Anatomic distribution of the lateral femoral cutaneous nerve (LFCN)

\begin{tabular}{|c|c|c|c|}
\hline Characteristics & Number of specimens $(n=30)$ & Mean \pm SD & Median (minimum-maximum) \\
\hline \multicolumn{4}{|l|}{ 1. Correlation of LFCN and TFL } \\
\hline On TFL & $19(63.3 \%)$ & & \\
\hline Under TFL & $11(36.7 \%)$ & & \\
\hline 2. Skin thickness (millimeter; mm) & & $3.6 \pm 1.8$ & $3.0(2.0-8.0)$ \\
\hline \multicolumn{4}{|l|}{ 3. Correlation of LFCN and ASIS at inguinal ligament level } \\
\hline Lateral to ASIS (mm) & $0(0.0 \%)$ & - & - \\
\hline Medial to ASIS (mm) & $30(100.0 \%)$ & $5.3 \pm 7.1$ & $3.0(0.0-29.0)$ \\
\hline \multicolumn{4}{|c|}{ 4. LFCN divided into branches correlated with the inguinal ligament } \\
\hline Divided proximally to inguinal ligament & $3(10 \%)$ & & \\
\hline Divided distally to inguinal ligament & $27(90 \%)$ & & \\
\hline 5. Number of branches & & $2.6 \pm 1.2$ & $2.0(1.0-6.0)$ \\
\hline 1 & $4(13.3 \%)$ & & \\
\hline 2 & $12(40.0 \%)$ & & \\
\hline 3 & $10(33.3 \%)$ & & \\
\hline$\geq 4$ & $4(13.3 \%)$ & & \\
\hline 6. Size of nerve (the largest branch) (mm) & & $3.6 \pm 1.3$ & $4.0(1.5-6.0)$ \\
\hline 7. Distance of nerve from ASIS to the nerve division (mm) & & $19.0 \pm 15.4$ & $15.5(1.0-56.0)$ \\
\hline 8. Distance of nerve from ASIS to the most distal part ( $\mathrm{mm})$ & & $115.0 \pm 32.0$ & $114.0(67.0-198.0)$ \\
\hline
\end{tabular}

the MDAA (Table 5). Additionally, functional outcome evaluated by HHS (89.0 and 91.2, $p=0.422)$ and pain score assessed by VAS ( 0.8 vs $0.6, p=0.314$ ) were comparable between patients without LFCN injury and those with LFCN injury (Table 6).

\section{Discussion}

Total hip arthroplasty can be performed in different approaches depending on the surgeon's experience. Direct anterior approach (DAA) is currently a standard approach to avoid high dislocation rate as seen in standard posterolateral approach [4] and to avoid abductor weakness and postoperative limp from the anterolateral approach [10]. Additionally, the DAA has several advantages including shorter length of hospital stay, faster recovery, and better functional outcome [19, 22]. However, this approach may cause damage to the lateral femoral cutaneous nerve (LFCN) as high as $81 \%$ in the literatures [18-20]. Understanding the relevant anatomy is important before performing a surgical approach because the LFCN had several anatomical variations [21, 23-28] and not much data has identified the LFCN in the Asian population. Therefore, the purpose of our study was to identify characteristics of the LFCN patterns representing an Asian hip, which would aid to provide the most appropriate incision of modified direct anterior approach (MDAA) for total hip arthroplasty (THA), and to identify the clinical outcome and complications following THA through the MDAA correlated with cadaveric hip in the Asian population.

Rudin et al. demonstrated that LFCNs were divided into 3 types with almost equal distribution $(36.0 \%$ in sartorius type, $32.0 \%$ in posterior type, and $32.0 \%$ in fan type) in European populations [21]. Another study by Sugano $M$ et al. classified this nerve into 2 types (37.0\% in anterior type and $63.0 \%$ in posterior type) and they did not identify the fan type pattern while $42.0 \%$ of all nerves crossed over the midline of tensor fascia lata [28]. Previous studies showed that injury to branches of LFCN cannot be avoided in almost onehalf of cadaveric dissection. Our study showed the difference in the LFCNs pattern. The LFCNs were predominantly in sartorius type pattern $(60.0 \%)$ and they were followed by posterior type (26.6\%), fan type $(6.7 \%)$, and variant type (6.7\%). Even though small area of skin numbness remained in 3 patients (9.4\%) at 1 year and 2 years follow-up, our cadaveric study possibly explained that fan type and variant type could not avoid the injury of LFCN (13.4\%). Interestingly, this study showed the different nerve characteristics compared with the previous literatures [21, 2428] and the clinical result after THA by the MDAA incision had a significantly lower rate of skin numbness $(9.4 \%)$ compared to Yasuhiro $\mathrm{H}$. et al.' s study (31.9\%). Therefore, an application of the MDAA can avoid injury to this nerve in clinical practice. 
Table 3 Patients demographics and comorbidities underwent THA through the MDAA

\begin{tabular}{|c|c|}
\hline Parameters & Result $(n=32)$ \\
\hline$\overline{\mathrm{Age}^{a}}$ & $61.2 \pm 14.5(26-87)$ \\
\hline \multicolumn{2}{|l|}{ Gender $^{\mathrm{b}}$} \\
\hline Female & $22(68.8 \%)$ \\
\hline Male & $10(31.2 \%)$ \\
\hline Body weight $(\mathrm{kg})^{\mathrm{a}}$ & $63.3 \pm 16.9(34-111)$ \\
\hline Height $(\mathrm{cm})^{\mathrm{a}}$ & $160.0 \pm 5.0(150-169)$ \\
\hline BMI $\left(\mathrm{kg} / \mathrm{m}^{2}\right)^{\mathrm{a}}$ & $24.7 \pm 6.3(14.0-40.9)$ \\
\hline \multicolumn{2}{|l|}{ Side for $T H A^{b}$} \\
\hline Right & $16(50.0 \%)$ \\
\hline Left & $16(50.0 \%)$ \\
\hline \multicolumn{2}{|c|}{ Cause of osteoarthritis $(\mathrm{OA})$ of the hip ${ }^{\mathrm{b}}$} \\
\hline Primary OA & $26(81.2 \%)$ \\
\hline Secondary OA & $6(18.8 \%)$ \\
\hline Length of stay (day) $)^{a}$ & $6.0 \pm 1.9(4-12)$ \\
\hline \multicolumn{2}{|l|}{ Hypertension ${ }^{b}$} \\
\hline Yes & $17(53.1 \%)$ \\
\hline No & 15 (46.9\%) \\
\hline \multicolumn{2}{|l|}{ Dyslipidemia $^{\mathrm{b}}$} \\
\hline Yes & $10(31.3 \%)$ \\
\hline No & $22(68.7 \%)$ \\
\hline \multicolumn{2}{|l|}{ ASA class ${ }^{b}$} \\
\hline 1 & $5(15.6 \%)$ \\
\hline 2 & $21(65.6 \%)$ \\
\hline 3 & $6(18.8 \%)$ \\
\hline $\mathrm{CCl}^{\mathrm{a}}$ & $2.8 \pm 0.9(2-5)$ \\
\hline
\end{tabular}

The modified direct anterior approach (MDAA); total hip arthroplasty (THA); American Society Anesthesiologist (ASA) classification; Charlson comorbidity index (CCl)

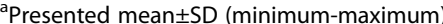

${ }^{\text {bPesented } n(\%)}$

Previous literatures demonstrated superior functional outcome after an anterior approach compared to a posterior approach [22, 29-32]. Mark WZ et al. defined that THA through the direct anterior approach allowed shorter recovery time at 6 weeks $(p<0.0001)$ and length of stay $(p<0.0001)$ compared to the mini-incision posterior approach [22]. Yasuhiro et al. showed that those THA patients without LFCN injury had a higher quality of life $(p=0.01)$ assessed by Forgotten Joint Scale (FJS12) than those THA patients with LFCN injury, while there was comparable functional outcome evaluated by WOMAC $(p=0.53)$ and Japanese Orthopaedic Association Hip Disease Evaluation Questionnaire (JHEQ) ( $p=$ 0.13) in both groups [33]. Additionally, Yu O. defined that there was similar functional outcome evaluated by WOMAC $(p=0.12)$ in the group without LFCN injury and the group with LFCN injury at an initial survey (1-
Table 4 Operative parameters, area of skin numbness (square centimeters), and their recovery time

\begin{tabular}{|c|c|}
\hline Parameters & $\begin{array}{l}\text { Primary THA through modified direct } \\
\text { anterior } \operatorname{approach}(n=32)\end{array}$ \\
\hline \multicolumn{2}{|c|}{ Operative parameters } \\
\hline $\begin{array}{l}\text { Operative time } \\
\text { (min) }\end{array}$ & $105.1 \pm 37.2(50.0-200.0)$ \\
\hline Blood loss (ml) & $664.1 \pm 340.1(100.0-1450.0)$ \\
\hline Skin incision* & $11.8 \pm 1.2(9.0-15.0)$ \\
\hline \multicolumn{2}{|l|}{ Numbness ${ }^{* * a}$} \\
\hline No & $23(71.9 \%)$ \\
\hline Yes & $9(28.1 \%)$ \\
\hline $\begin{array}{l}\text { Area of skin } \\
\text { numbness }\left(\mathrm{cm}^{2}\right)^{*}\end{array}$ & The group with LFCN injury $(n=9)$ \\
\hline 6 weeks $(n=9)$ & $234 \pm 167.8(56.3-600.0)$ \\
\hline 3 months $(n=9)$ & $172.3 \pm 127.9(56.3-450.0)$ \\
\hline 6 months $(n=5)$ & $140.0 \pm 84.0(25.0-200.0)$ \\
\hline 1 year $(n=5)$ & $125.0 \pm 43.3(75.0-150.0)$ \\
\hline 1.5 year $(n=3)$ & $96.0 \pm 55.1(40.0-150.0)$ \\
\hline 2 years $(n=3)$ & $96.0 \pm 55.1(40.0-150.0)$ \\
\hline
\end{tabular}

Recovery of numbness (months)*

Mean \pm SD (min-max); $12.6 \pm 9.2$ (3.0-24.0); 12.0 median

$\begin{array}{ll}\text { Rate of skin numbness }^{* *} \\ 6 \text { weeks } & 9(28.1 \%) \\ 3 \text { months } & 9(28.1 \%) \\ 6 \text { months } & 5(15.6 \%) \\ 1 \text { year } & 3(9.4 \%) \\ 1.5 \text { year } & 3(9.4 \%) \\ 2 \text { years } & 3(9.4 \%)\end{array}$

All of the 3 patients had approximately $40 \%$ remaining skin numbness at 2 years follow-up (FU) compared to 6 weeks FU

a Represented the prevalence of skin numbness occurred $28.1 \%(n=9)$ from

32 patients that was consistent with our hypothesis

year follow-up), but those with an LFCN injury with spontaneous nerve healing (2-year follow-up) were associated with a better quality of life assessed by WOMAC $(p=0.005)$, JHEQ $(p=0.003)$, and FJS-12 $(p=0.02)$ compared to those without spontaneous nerve healing [34]. Our study showed no significant difference in functional score at 2 years follow-up (89.0 vs 91.2, $p=0.422$ ) between those with LFCN injury and those without LFCN injury that were similar to previous studies [33, 34].

This study firstly identified the combination of LFCN patterns from a cadaveric study and further adjusted the modified incision (the MDAA) to decrease the possibility of the LFCN injury during THA in a real clinical setting. This is additional information for clinical guidance for all orthopedists who performed THA through the direct anterior approach. 
Table 5 Functional outcome and complications after THA through the MDAA in all patients

\begin{tabular}{|c|c|}
\hline Parameters & $\begin{array}{l}\text { Result } \\
(n=32)\end{array}$ \\
\hline \multicolumn{2}{|l|}{ Harris hip score (HHS) ${ }^{a}$} \\
\hline Preoperative HHS & $42.8 \pm 14.8(28.0-79.0)$ \\
\hline Postoperative HHS & $89.6 \pm 7.0(75.0-100.0)$ \\
\hline$P$ value & $<0.001$ \\
\hline \multicolumn{2}{|l|}{ Visual analog score (VAS) ${ }^{a}$} \\
\hline Preoperative VAS & $8.2 \pm 1.1(6.0-10.0)$ \\
\hline Postoperative VAS & $0.8 \pm 0.7(0.0-2.0)$ \\
\hline$P$ value & $<0.001$ \\
\hline \multicolumn{2}{|l|}{ Wound complication ${ }^{b}$} \\
\hline Wound dehiscence & $0(0.0 \%)$ \\
\hline Superficial infection & $0(0.0 \%)$ \\
\hline Periprosthetic joint infection ${ }^{b}$ & $0(0.0 \%)$ \\
\hline Meralgia paresthetica ${ }^{b}$ & $0(0.0 \%)$ \\
\hline Abductor weakness ${ }^{b}$ & $0(0.0 \%)$ \\
\hline Venous thromboembolism ${ }^{b}$ & $0(0.0 \%)$ \\
\hline Mortality ${ }^{b, c}$ & 1 (3.1\%) \\
\hline
\end{tabular}

The modified direct anterior approach (MDAA); Total hip arthroplasty (THA) ${ }^{\text {a }}$ resented mean \pm SD (minimum-maximum)

${ }^{\mathrm{b}}$ Represented $n$ (\%)

'One patient died after 2 years follow-up ( 3 years after THA from pneumonia with sepsis)

Table 6 A comparison of functional outcome and pain score between those patients with LFCN injury and those patients without LFCN injury

\begin{tabular}{llll}
\hline Parameters & $\begin{array}{l}\text { LFCN injury } \\
(\boldsymbol{n}=\mathbf{9})\end{array}$ & $\begin{array}{l}\text { Without LFCN } \\
\text { injury }(\boldsymbol{n}=\mathbf{2 3})\end{array}$ & $\boldsymbol{P}$ value \\
\hline Harris hip score (HHS) & & & \\
Pre HHS & $41.7 \pm 8.3$ & $43.3 \pm 14.1$ & 0.754 \\
Post HHS & $91.2 \pm 8.3$ & $89.0 \pm 6.6$ & 0.422 \\
HHS difference & $49.6 \pm 9.8$ & $45.7 \pm 14.4$ & 0.467 \\
Visual analog score (VAS) & & \\
Pre-VAS & $8.4 \pm 1.1$ & $8.1 \pm 1.1$ & 0.488 \\
Post-VAS & $0.6 \pm 0.7$ & $0.8 \pm 0.7$ & 0.314 \\
VAS difference & $7.9 \pm 1.5$ & $7.3 \pm 1.2$ & 0.248 \\
\hline
\end{tabular}

\section{Conclusion}

Direct anterior approach causing damage to the lateral femoral cutaneous nerve (LFCN) is not uncommon. This study found that the LFCNs were divided into four types from cadaveric study. The modified direct anterior approach decreases the possibility of the LFCN injury, which is an alternative approach for THA allowing for a lower rate of skin numbness without hip dislocation, abductor weakness, and serious nerve complication. Functional outcome was comparable with and without LFCN injury.

\section{Abbreviations \\ LFCN: Lateral femoral cutaneous nerve of thigh; Modified DAA: Modified direct anterior approach; THA: Total hip arthroplasty; ASIS: Anterior superior iliac spine; TFL: Tensor fascia lata; OA: Osteoarthritis; ASA: American Society of Anesthesiologists classification; CCl: Charlson comorbidity index; VAS: Visual analog scale; HHS: Harris hip score; WOMAC: Western Ontario and McMaster Universities Arthritis Index; FJS: Forgotten joint scale; JHEQ: Japanese Orthopaedic Association Hip disease Evaluation Questionnaire}

\section{Acknowledgements}

We thank you Professor John J. Callaghan for his encouragement and advice during our study. We also thank Kevin Mack Maikoksoong for English correction.

\section{Authors' contributions}

All authors designed the protocol, read, and approved the final manuscript. O.P.: generating the idea, dissection the cadavers, collecting data, and writing manuscript. V.S. and T.C.: sorted out the material and assisted in the discussion part. S.T. and N.A.: assisted during dissection of the cadavers and assisted in the discussion part. M.C.: supervised the study, dissection the cadavers, revised the manuscript.

Funding

There is no funding for this article.

\section{Availability of data and materials}

The datasets used and/or analyzed during the current study are available from the corresponding author on reasonable request.

\section{Declarations}

Ethics approval and consent to participate

This study followed the "Declaration of Helsinki" and was approved by the Institutional Review Board of University of lowa Hospital and Clinics.

Consent for publication

Consent was obtained from all patients to publish quotations anonymously.

\section{Competing interests}

The authors declare that they have no competing interests.

\section{Author details}

'Orthopedic Department, Phramongkutklao Hospital, 315 Ratchvidhi Road, Thung Phaya Thai, Ratchathewee, Bangkok 10400, Thailand. ${ }^{2}$ Department of Anatomy, Phramongkutklao College of Medicine, Bangkok, Thailand.

Received: 2 June 2021 Accepted: 11 August 2021

Published online: 20 August 2021

\section{References}

1. Ethgen $\mathrm{O}$, Bruyere $\mathrm{O}$, Richy F, et al. Health-related quality of life in total hip and total knee arthroplasty: a quality and systematic review of the literature. J Bone Joint Surg Am. 2004;86-A:963.

2. Jones CA, Voaklander DC, Johnston DW, et al. Health related quality of life outcomes after total hip and knee arthroplasties in a community-based population. J Rheumatol. 2000;27:1745. 
3. Vicar AJ, Coleman CR. A comparison of the anterolateral, transtrochanteric, and posterior surgical approaches in primary total hip arthroplasty. Clin Orthop Relat Res. 1984;188:152-9.

4. DeWal H, Su E, DiCesare PE. Instability following total hip arthroplasty. Am J Orthop. 2003;32(8):377-82.

5. Matta JM. Bilateral THA. Orthopedics. 2002;25(11):1224. https://doi.org/10.392 8/0147-7447-20021101-05.

6. McCollum DE, Gray WJ. Dislocation after total hip arthroplasty: causes and prevention. Clin Orthop Relat Res. 1990;261:159-70.

7. Robbins GM, Masri BA, Garbuz DS, Greidanus N, Duncan CP. Treatment of hip instability. Orthop Clin North Am. 2001;32(4):593-610. https://doi.org/1 0.1016/S0030-5898(05)70230-3.

8. Baker AS, Bitounis VC. Abductor function after total hip replacement: an electromyographic and clinical review. J Bone Joint Surg. 1985;71B:47-50.

9. Horwitz BR, Rockowitz NL, Goll SR, et al. A prospective randomized comparison of two surgical approaches to total hip arthroplasty. Clin Orthop Relat Res. 1993;291:154-63.

10. Matta JM, Shahrdar C, Ferguson T. Single-incision anterior approach for total hip arthroplasty on an orthopaedic table. Clin Orthop Relat Res. 2005; 441(12):115-24. https://doi.org/10.1097/01.blo.0000194309.70518.cb.

11. Siguier T, Siguier M, Brumpt B. Mini-incision anterior approach does not increase dislocation rate: a study of 1037 total hip replacements. Clin Orthop Relat Res. 2004;426(9):164-73. https://doi.org/10.1097/01.blo.000013 6651.21191.9f

12. Laude F, Sariali E. Treatment of FAl via a minimally invasive ventra approach with arthroscopic assistance: technique and midterm results. Orthopade. 2009;38(5):419-28. https://doi.org/10.1007/s00132-008-1387-1.

13. Clohisy JC, Zebala LP, Nepple JJ, Pashos G. Combined hip arthroscopy and limited open osteochondroplasty for anterior femoroacetabular impingement. J Bone Joint Surg Am. 2010;92(8):1697-706. https://doi.org/1 0.2106/JBJS.I.00326.

14. Pemberton PA. Pericapsular osteotomy of the ilium for treatment of congenital subluxation and dislocation of the hip. J Bone Joint Surg Am. 1965:47(1):65-86. https://doi.org/10.2106/00004623-196547010-00004.

15. Ganz R, Klaue K, Vinh TS, Mast JW. A new periacetabular osteotomy for the treatment of hip dysplasias: technique and preliminary results. Clin Orthop Relat Res. 2004;418(1):3-8. https://doi.org/10.1097/00003086-20040100000002.

16. Salter RB, Hansson G, Thompson GH. Innominate osteotomy in the management of residual congenital subluxation of the hip in young adults. Clin Orthop Relat Res. 1984;182(1):53-68.

17. Griffin DB. Beaule' PE, Matta JM. Safety and efficacy of the extended iliofemoral approach in the treatment of complex fractures of the acetabulum. J Bone Joint Surg (Br). 2005;87(10):1391-6.

18. Goulding K. Beaule' PE, Kim PR, Fazekas A. Incidence of lateral femoral cutaneous nerve neuropraxia after anterior approach hip arthroplasty. Clin Orthop Relat Res. 2010;468(9):2397-404. https://doi.org/10.1007/s11999-01 0-1406-5.

19. Restrepo C, Parvizi J, Pour AE, Hozack WJ. Prospective randomized study of 2 surgical approaches for total hip arthroplasty. J Arthroplast. 2010;25(5): 671-9. https://doi.org/10.1016/j.arth.2010.02.002

20. Homma Y, Baba T, Sano K, Ochi H, Matsumoto M, Kobayashi H, et al. Lateral femoral cutaneous nerve injury with the direct anterior approach for total hip arthroplasty. Int Orthop. 2016;40(8):1587-93. https://doi.org/10.1007/s002 64-015-2942-0.

21. Rudin D, Manestar M. MD, Oliver Ullrich, et al. The anatomical course of the lateral femoral cutaneous nerve with special attention to the anterior approach to the hip joint. J Bone Joint Surg Am. 2016;98(7):561-7. https:// doi.org/10.2106/JBJS.15.01022.

22. Zawadsky MW, Paulus MC, Patrick J. Murray, et al. Early outcome comparison between the direct anterior approach and the mini-incision posterior approach for primary total hip arthroplasty: 150 consecutive cases. J Arthroplast. 2014;29(6):1256-60. https://doi.org/10.1016/j.arth.2013.11.013.

23. Hoppenfeld S, deBoer P, Buckley R. Surgical exposures in orthopaedics: the anatomic approach. 4th ed. Philadelphia: Lippincott Williams \& Wilkins; 2009.

24. Murata $Y$, Takahashi $K$, Masatsune $Y$, Yutaka S, Hideshige M. The anatomy of the lateral femoral cutaneous nerve, with special reference to the harvesting of iliac bone graft. J Bone Joint Surg Am. 2000;82(5):746-7. https://doi.org/10.2106/00004623-200005000-00016.
25. Hospodar PP, Ashman ES, Traub JA. Anatomic study of the lateral femoral cutaneous nerve with respect to the ilioinguinal surgical dissection. J Orthop Trauma. 1999;13(1):17-9. https://doi.org/10.1097/00005131-199901 000-00005.

26. De Ridder VA, De Lange S, Popta JV. Anatomical variations of the lateral femoral cutaneous nerve and the consequences for surgery. J Orthop Trauma. 1999;13(3):207-11. https://doi.org/10.1097/00005131-19990300000009.

27. Doklamyai P, Agthong S, Chentanez V, Huanmanop T, Amarase C, Surunchupakorn P. Anatomy of the lateral femoral cutaneous nerve related to inguinal ligament, adjacent bony landmarks, and femoral artery. Clin Anat. 2008;21(8):769-74. https://doi.org/10.1002/ca.20716

28. Sugano M, Nakamura J, Hagiwara S, Suzuki T, Nakajima T, Orita S, et al. Anatomical course of lateral femoral cutaneous nerve with special reference to the direct anterior approach to total hip arthroplasty. Mod Rheumatol. 2020;30(4):752-7. https://doi.org/10.1080/14397595.2019.1637992.

29. Restrepo C, Parvizi J, Pour A, et al. Prospective randomized study of two surgical approaches for total hip arthroplasty. J Arthroplast. 2010;25(5):671679.e1. https://doi.org/10.1016/j.arth.2010.02.002.

30. Nakata K, Nishikawa M, Yamamoto K, Hirota S, Yoshikawa H. A clinical comparative study of the direct anterior with mini posterior approach. $J$ Arthroplast. 2009;24(5):698-704. https://doi.org/10.1016/j.arth.2008.04.012.

31. Bergin PF, Doppelt JD, Kephart CJ, Benke MT, Graeter JH, Holmes AS, et al. Comparison of minimally invasive direct anterior versus posterior total hip arthroplasty based on inflammation and muscle damage markers. J Bone Joint Surg Am. 2011:93(15):1392-8. https://doi.org/10.2106/JBJS.J.00557.

32. Martin CT, Pugely AJ, Gao Y, et al. A comparison of hospital length of stay and short term morbidity between the anterior and the posterior approaches to total hip arthroplasty. J Arthroplasty. 2013;28(5):849-54. https://doi.org/10.1016/j.arth.2012.10.029.

33. Yasuhiro H, Tomonori B, Kei S, et al. Lateral femoral cutaneous nerve injury with the direct anterior approach for total hip arthroplasty. Int Orthopaedics (SICOT). 2016. https://doi.org/10.1007/s00264-015-2942-0.

34. Yu O, Yasuhiro H, Tomonori B, et al. Spontaneous healing of lateral femoral cutaneous nerve injury and improved quality of life after total hip arthroplasty via a direct anterior approach: survey at average 12.8 and 26.2 months of follow-up. J Orthop Surg. 2017;25(1):1-7.

\section{Publisher's Note}

Springer Nature remains neutral with regard to jurisdictional claims in published maps and institutional affiliations.

Ready to submit your research? Choose BMC and benefit from:

- fast, convenient online submission

- thorough peer review by experienced researchers in your field

- rapid publication on acceptance

- support for research data, including large and complex data types

- gold Open Access which fosters wider collaboration and increased citations

- maximum visibility for your research: over $100 \mathrm{M}$ website views per year

At $\mathrm{BMC}$, research is always in progress.

Learn more biomedcentral.com/submission 